\title{
A Validated Liquid Chromatographic Method for the Determination of Solifenacin Succinate (Urinary Antispasmodic) in Tablets
}

\author{
M. MATHRUSRI ANNAPURNA*, G. SOWJANYA, \\ M. SANTOSH NAIDU and D. LOHITHASU
}

GITAM Institute of Pharmacy, GITAM University, Visakhapatnam, India mathrusri2000@yahoo.com

Received 31 January 2014 / Accepted 19 February 2014

\begin{abstract}
An isocratic reversed-phase liquid chromatographic method was developed and validated for the determination of Solifenacin succinate. Chromatographic separation was achieved on a $\mathrm{C}_{18}$ column using an aqueous tetra butyl ammonium hydrogen sulphate $(10 \mathrm{mM})$ : acetonitrile $(40: 60, \mathrm{v} / \mathrm{v})$, with flow rate $0.8 \mathrm{~mL} / \mathrm{min}$ (UV detection at $254 \mathrm{~nm}$ ). Linearity was observed in the concentration range of $20-200 \mu \mathrm{g} / \mathrm{mL}\left(\mathrm{R}^{2}=0.999\right)$. The limit of quantitation was found to be $0.845 \mu \mathrm{g} / \mathrm{mL}$ and the limit of detection was found to be $0.0269 \mu \mathrm{g} / \mathrm{mL}$. The method was validated as per ICH guidelines. The method is simple, precise, robust and accurate for the determination of Solifenacin in tablet dosage forms.
\end{abstract}

Keywords: RP-HPLC, Solifenacin succinate, Validation, Tablets

\section{Introduction}

Chemically, Solifenacin ${ }^{1}$ (SLFN) is 1-azabicyclo [2.2.2] oct-8-yl (1S)-1-phenyl-3,4- dihydro$1 \mathrm{H}$-isoquinoline-2-carboxylate with an empirical formula of $\mathrm{C}_{23} \mathrm{H}_{26} \mathrm{~N}_{2} \mathrm{O}_{2} \cdot \mathrm{C}_{4} \mathrm{H}_{6} \mathrm{O}_{4}$ (Figure 1) and a molecular weight of 480.55 . It is generally used as a succinate. Solifenacin succinate is a white to pale-yellowish-white crystal or crystalline powder and freely soluble at room temperature in water, glacial acetic acid, dimethyl sulfoxide, and methanol. Solifenacin is a urinary antispasmodic (Anti-muscarinic class). It acts as a direct antagonist at muscarinic acetylcholine receptors in cholinergically innervated organs. Its anticholinergicparasympatholytic action ${ }^{2}$ reduces the tonus of smooth muscle in the bladder, effectively reducing the number of required voids, urge incontinence episodes, urge severity and improving retention, facilitating increased volume per void. Literature survey revealed that few HPLC $^{3-11}$, LC-MS ${ }^{12-13}$, HPTLC ${ }^{14-15}$ gas chromatography ${ }^{16}$ and spectroscopic ${ }^{17-18}$ methods have been reported for the determination of Solifenacin succinate in tablet dosage forms as well as in biological matrices. An attempt has been made to develop a simple and rapid reverse phase liquid chromatographic method for the determination of Solifenacin succinaten in tablet dosage forms which was validated according to $\mathrm{ICH}$ guidelines ${ }^{19}$. 


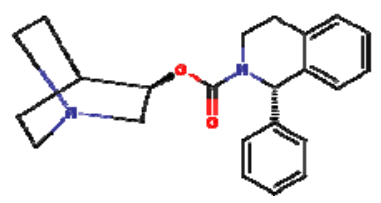

Figure 1. Chemical structure of Solifenacin

\section{Experimental}

Solifenacin standard (purity 98.0-101.0) was obtained from Dr. Reddy's laboratories, Hyderabad. Acetonitrile and water (HPLC grade) were obtained from Merck (India). Solifenacin is available (Label claim: $10 \mathrm{mg}$ ) with brand names BISPEC (Dr. Reddy's laboratories, India) and SOLITEN (Ranbaxy laboratories Ltd., India). All chemicals were of analytical grade and used as received.

\section{Preparation of tetra butyl ammonium hydrogen sulphate $(10 \mathrm{mM})$ solution}

3.3954 grams of tetra butyl ammonium hydrogen sulphate (TBAHS) was transferred to a $1000 \mathrm{ml}$ volumetric flask and dissolved in HPLC grade water ( $\mathrm{pH} 3.37$ ).

\section{Preparation of solifenacin stock solution}

Solifenacin stock solution $(1000 \mu \mathrm{g} / \mathrm{mL})$ was prepared by accurately weighing $25 \mathrm{mg}$ of SLFN in a $25 \mathrm{~mL}$ volumetric flask with mobile phase. Working standard solutions were prepared on a daily basis from the stock solution in a solvent mixture of TBAHS $(\mathrm{pH} 3.37)$ and acetonitrile $(40: 60, \mathrm{v} / \mathrm{v})$. Solutions were filtered through a $0.45 \mu \mathrm{m}$ membrane filter prior to injection.

\section{Instrumentation and chromatographic conditions}

Chromatographic separation was achieved by using a Shimadzu Model CBM-20A/20 Alite HPLC system, equipped with SPD M20A prominence photodiode array detector with C18 $\left(250 \mathrm{~mm} \times 4.6 \mathrm{~mm}\right.$ i.d., $5 \mu \mathrm{m}$ particle size) column maintained at $25^{\circ} \mathrm{C}$. Isocratic elution was performed using tetra butyl ammonium hydrogen sulphate (TBAHS) ( $\mathrm{pH} \mathrm{3.37)}$ and acetonitrile $(40: 60, \mathrm{v} / \mathrm{v})$. The overall run time was $10 \mathrm{~min}$. and the flow rate was $0.8 \mathrm{~mL} / \mathrm{min}$. $20 \mu \mathrm{L}$ of sample was injected into the HPLC system.

\section{Method validation}

The method was validated for the following parameters: system suitability, linearity, limit of quantitation (LOQ), limit of detection (LOD), precision, accuracy and robustness.

\section{Linearity}

Linearity test solutions for the assay method were prepared from a stock solution at different concentration levels $(20-200 \mu \mathrm{g} / \mathrm{mL})$ of the assay analyte concentration, $20 \mu \mathrm{L}$ of each solution was injected in to the HPLC system and the peak area of the chromatogram obtained was noted. The calibration curve was plotted by taking the concentration on the x-axis and the corresponding peak area on the y-axis. The data was treated with linear regression analysis method.

\section{Precision}

The intra-day precision of the assay method was evaluated by carrying out 9 independent assays of a test sample of SLFN at three concentration levels $(40,80$ and $100 \mu \mathrm{g} / \mathrm{mL})(\mathrm{n}=3)$ against a qualified reference standard. The RSD of three obtained assay values at three different concentration levels was calculated. The inter-day precision study was performed on three different days i.e. day 1 , day 2 and day 3 at three different concentration levels (40, 80 and $100 \mu \mathrm{g} / \mathrm{mL}$ ) and each value is the average of three determinations ( $\mathrm{n}=3$ ). The RSD of three obtained assay values on three different days was calculated. 


\section{Accuracy}

The accuracy of the assay method was evaluated in triplicate at three concentration levels $(80 \%, 100 \%$ and $120 \%)$ and the percentage recoveries were calculated. Standard addition and recovery experiments were conducted to determine the accuracy of the method for the quantification of SLFN in the drug product. The study was carried out in triplicate at 90, 100 and $110 \mu \mathrm{g} / \mathrm{mL}$. The percentage recovery in each case was calculated.

\section{Robustness}

The robustness of the assay method was established by introducing small changes in the HPLC conditions which included wavelength (249 and $259 \mathrm{~nm})$, percentage of acetonitrile in the mobile phase (62 and 58) and flow rate $(0.7$ and $0.9 \mathrm{~mL} / \mathrm{min})$. Robustness of the method was studied using six replicates at a concentration level of $100 \mu \mathrm{g} / \mathrm{mL}$ of Solifenacin.

\section{Analysis of marketed formulations}

The content of 25 tablets (each containing $10.0 \mathrm{mg}$ of SLFN) was mixed and quantity equivalent to $25 \mathrm{mg}$ of drug weighed accurately and dissolved in mobile phase in a $25 \mathrm{~mL}$ volumetric flask, sonicated and filtered. The filtrate was diluted as per the requirement and $20 \mu \mathrm{L}$ solution of each of marketed formulations (BISPEC and SOLITEN) was injected in to the HPLC system for conducting the assay.

\section{Results and Discussion}

A reversed-phase liquid chromatographic technique was developed to determine Solifenacin in tablet dosage forms. Satisfactory resolution was achieved with use of a mixture of TBAHS and acetonitrile (40:60, v/v) and C18 column was adopted (UV detection at $254 \mathrm{~nm}$ ) (PDA detector).

\section{HPLC method development and optimization}

Initially the samples were analyzed using a mobile phase consisting of TBAHS: acetonitrile $(90: 10, \mathrm{v} / \mathrm{v})$ at a flow rate of $1.0 \mathrm{~mL} / \mathrm{min}$. Under these no drug peak was observed and so the mobile phase was changed to TBAHS: acetonitrile 70:30, 20:80, 30:70 and finally to 40:60, $\mathrm{v} / \mathrm{v}$ with a flow rate $0.8 \mathrm{~mL} \mathrm{~min}^{-1}$ has given a sharp peak at 3.07 min which was chosen as the best chromatographic response for the entire study. The typical chromatogram for Solifenacin was shown in Figure 2.

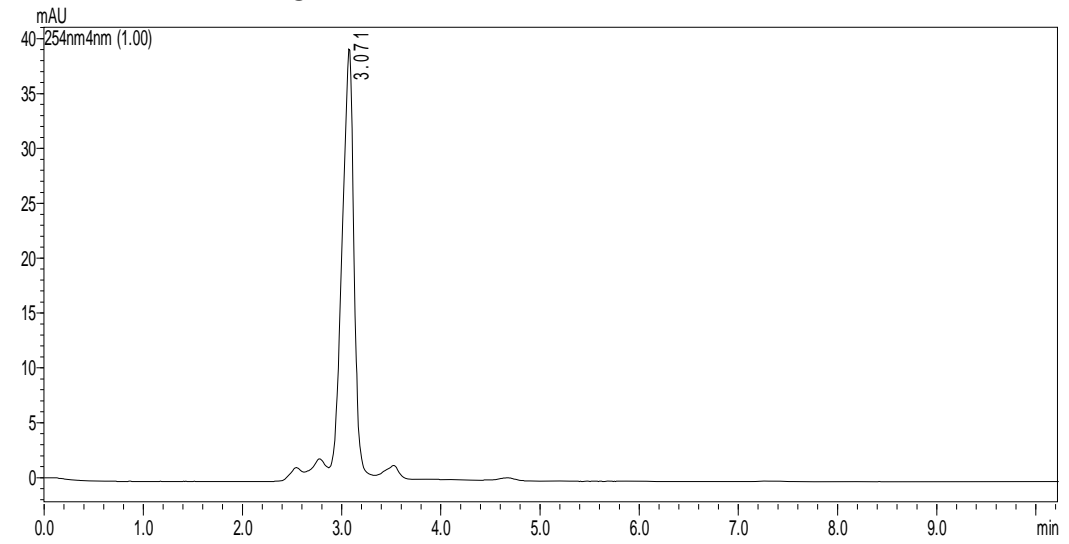

Figure 2. Typical chromatogram of Solifenacin succinate $(200 \mu \mathrm{g} / \mathrm{mL})$ 


\section{Method validation}

\section{Linearity}

Solifenacin has shown linearity over the concentration range $20-200 \mu \mathrm{g} / \mathrm{mL}$ (Table 1). A graph was drawn by taking the concentration of the drug on the $\mathrm{x}$-axis and the corresponding peak area on the y-axis (Figure 3). The linear regression equation was found to be $y=1644 x-753.9$ with correlation coefficient 0.999 .

Table 1. Linearity of Solifenacin succinate

\begin{tabular}{|c|c|c|}
\hline Conc. $\mu \mathrm{g} / \mathrm{mL}$ & Mean peak area ${ }^{*} \pm \mathrm{SD}$ & RSD \\
\hline 20 & $32946 \pm 279.0$ & 0.85 \\
\hline 40 & $66195 \pm 337.4$ & 0.51 \\
\hline 50 & $80660 \pm 463.0$ & 0.57 \\
\hline 80 & $131779 \pm 455.3$ & 0.35 \\
\hline 100 & $160820 \pm 497.6$ & 0.31 \\
\hline 150 & $241640 \pm 1388.3$ & 0.57 \\
\hline 200 & $332079 \pm 1607.8$ & 0.48 \\
\hline \multicolumn{3}{|c|}{${ }^{*}$ Mean of three replicates } \\
\hline 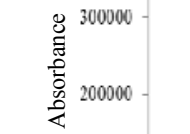 & $\begin{array}{c}y-1641 x-7539 \\
K^{\prime}-0.9 y 9\end{array}$ & \\
\hline 100000 & & \\
\hline 0 & 150 & \\
\hline
\end{tabular}

\section{Precision}

Figure 3. Calibration curve of Solifenacin succinate

The precision of the method was determined by repeatability (intra-day precision) and intermediate precision (inter-day precision) of the SLFN standard solutions. Repeatability was calculated by assaying three samples of each at three different concentration levels (40, 80 and $100 \mu \mathrm{g} / \mathrm{mL}$ ) on the same day. The inter-day precision was calculated by assaying three samples of each at three different concentration levels $(40,80$ and $100 \mu \mathrm{g} / \mathrm{mL})$ on three different days. The RSD range was obtained as $0.39-0.66$ and $0.41-0.53$ for intra-day and inter-day precision studies respectively (Table 2).

\section{Accuracy/recovery studies}

The method accuracy was proven by the recovery test. Known amounts of SLFN standard was added to aliquots of samples solutions and then diluted to yield total concentrations as 90, 100 and $110 \mu \mathrm{g} / \mathrm{mL}$ as described in Table 2 . The assay was repeated over three consecutive days. The resultant RSD was in the range 0.35-0.59 $(<2.0)$ with a recovery 99.09-100.08.

\section{Robustness}

The robustness of an analytical procedure refers to its ability to remain unaffected by small and deliberate variations in method parameters and provides an indication of its reliability for routine analysis. The robustness of the method was evaluated by assaying the same sample 
under different analytical conditions deliberately changing from the original condition and the RSD was less than $2.0(0.35-1.06)$ indicating that the proposed method was robust (Table 3$)$.

Table 2. Precision and accuracy study of Solifenacin succinate

\begin{tabular}{|c|c|c|c|}
\hline \multirow{2}{*}{ Conc. $\mu \mathrm{g} / \mathrm{mL}$} & Intra-day precision & \multicolumn{2}{|c|}{ Inter-day precision } \\
\hline & ${ }^{*}$ Mean peak area \pm SD $(\mathrm{RSD})$ & \multicolumn{2}{|c|}{${ }^{*}$ Mean peak area \pm SD (RSD) } \\
\hline 40 & $66128 \pm 259.92(0.39)$ & \multicolumn{2}{|c|}{$66301 \pm 282.40(0.43)$} \\
\hline 80 & $132519 \pm 879.43(0.66)$ & \multicolumn{2}{|c|}{$132514 \pm 695.88(0.53)$} \\
\hline 100 & $161154 \pm 920.23(0.57)$ & \multicolumn{2}{|c|}{$161514 \pm 655.05(0.41)$} \\
\hline \multicolumn{4}{|c|}{ Accuracy } \\
\hline Conc. $\mu \mathrm{g} / \mathrm{mL}$ & ${ }^{*}$ Mean peak area \pm SD (RSD) & Drug found $\mu \mathrm{g} / \mathrm{mL}$ & Recovery \\
\hline 90 & $145600 \pm 676.37(0.46)$ & 89.21 & 99.09 \\
\hline 100 & $161452 \pm 952.96(0.59)$ & 100.08 & 100.08 \\
\hline 110 & $177507 \pm 616.05(0.35)$ & 109.82 & 99.84 \\
\hline
\end{tabular}

"Mean of three replicates

Table 3. Robustness study of Solifenacin succinate

\begin{tabular}{cccc}
\hline Parameter & Condition & Mean peak area \pm SD (RSD) & Recovery \\
\hline Mobile phase & $38: 62$ & $161795 \pm 566.82$ & \\
composition & $40: 60$ & $(0.35)$ & 99.8 \\
$( \pm 2)$ & $42: 58$ & $162154 \pm 1712.38$ & \\
Flow rate & 0.7 & $(1.06)$ & 100.1 \\
$( \pm 0.1 \mathrm{~mL})$ & 0.8 & $161191 \pm 996.03$ & \\
& 0.9 & $(0.62)$ & 99.5 \\
UV detection & 249 & 254 &
\end{tabular}

\section{System suitability}

*Mean of three replicates

The system suitability test was performed to ensure that the complete testing system was suitable for the intended application. The capacity factor was more than 2, theoretical plates were more than 2000 and tailing factor was less than 2 for the SLFN peak. The peak purity index was found to be 1.0000 . The LOQ was found to be $0.845 \mu \mathrm{g} / \mathrm{mL}$ and the LOD was found to be $0.269 \mu \mathrm{g} / \mathrm{mL}$.

\section{Analysis of commercial formulations (Tablets)}

The proposed method was applied for the determination of Solifenacin in tablets (BISPEC and SOLITEN). The percentage of purity was found to be 99.11- 100.33 (Table 4) and no interference was observed from the excipients of the tablets.

Table 4. Assay of Solifenacin succinate (Tablets)

\begin{tabular}{cccc}
\hline Formulation & Labeled claim, mg & ${ }^{*}$ Amount found $\mathrm{mg}$ & ${ }^{*}$ Recovery(\%) \pm SD \\
\hline BISPEC $^{\circledR}$ & 10 & 10.03 & $100.33 \pm 0.75$ \\
SOLITEN $^{\circledR}$ & 10 & 9.87 & $99.11 \pm 0.51$ \\
\hline
\end{tabular}

\section{Conclusion}

*Mean of three replicates

The proposed liquid chromatographic method for the determination of Solifenacin succinate 
is precise, accurate, robust and can be applied for the determination of Solifenacin in pharmaceutical dosage forms.

\section{Acknowledgement}

We are grateful to M/s GITAM University, Visakhapatnam, India for providing research facilities and Dr. Reddy's Laboratories (India) for providing the gift samples of Solifenacin succinate.

\section{References}

1. Ơ Neil M J, The Merck Index, $14^{\text {th }}$ Edition, Merck Research Laboratories, Whitehouse Station, New Jersey, 2006.

2. Smulders R A, Krauwinkel W J, Swart P J and Huang M, J Clinical Pharmacology, 2004, 44(9), 1023-1033; DOI:10.1177/0091270004267592

3. Rami Reddy B V, Srinivasa Reddy B, Raman N V V S S, Subhash Reddy K and Rambabu C, J Chem., 2013, Article ID 412353, 10 pages; DOI: $10.1155 / 2013 / 412335$

4. Vijayasree V, Anantha Kumar D and Seshagiri Rao J V L N, Pharmanest, 2013, 4(2), 206-212.

5. Saroj Kumar Raul, Ravi Kumar B V V and Ajaya Kumar Patnaik, Int J Bioassays, 2012, 1(12), 210-213.

6. Nageswara Rao K, Ganapaty S and Lakshmana Rao A, An Int J Adv Pharm Sci., 2012, 3(5), 366-374.

7. Desai D, Patel G, Shukla N and Rajput S, Acta Chromatogr., 2012, 24 (3), 399-418.

8. Nilesh desai, Syed Sajjad Hussen, Vasanthraju SG, Karthik A and Udupa N, Int J Pharm Pharm Sci, 2011, 3(1), 70-74.

9. Shashikant B Landge, Sanjay A Jadhav, Sunil B Dahale, Navanath C Niphade, Ch Lakshmi Narayana, Vishwas B Gaikwad and Vijayavitthal T Mathad, Chromatogr Res Int, 2011, Article ID 243491, 7 pages; DOI:10.4061/2011/243491

10. Radha Krishna S, Rao BM and Someswara Rao N, J Chromatogr Sci., 2010, 48(10), 807-810; DOI:10.1093/chromsci/48.10.807

11. Takamitsu Yanagihara, Toshiko Aoki, Yoshiaki Soeishi, Takafumi Iwatsubo and Hidetaka Kamimura, J Chromatogr B Analyt Technol Biomed Life Sci., 2007, 859(2), 241-245; DOI:10.1016/j.jchromb.2007.10.005

12. Macek J, Ptacek P and Klima J, J Chromatogr B, 2010, 878(31), 3327-3330; DOI:10.1016/j.jchromb.2010.10.010

13. Mistri Hiren N, Jangid Arvind G, Pudage Ashutosh, Dhiraj M Rathod and Pranav S Shrivastav, J Chromatogr B, 2008, 876(2), 236-244;

DOI:10.1016/j.jchromb.2008.10.050

14. Wankhede S B, Kratika Somani and Chitlange S S, Int J Chem Tech Res., 2011, 3(4), 2003-2010.

15. Diti J Desai, Greeshma Patel, Dipti Ruikar, Reshma A Jain and Sadhana J Rajput, Asian J Pharm Biol Res., 2011, 1(3), 310-316.

16. Narendra Kumar M, Krishna Reddy V, Hemant Kumar Sharma, Madhava Reddy P, Raju K V S N, Pradeep Rajputa and Kaleemullah T, Chem Sci Trans., 2012, 1(2), 415-423; DOI:10.7598/cst2012.156

17. Lokesh Singh and Sanju Nanda, Pharmaceutical Methods, 2011, 2(1), 21-24; DOI:10.4103/2229-4708.81086

18. Seetharaman R and Lakshmi K S, Int J Res Pharm Biomed Sci., 2011, 2(3), 1052-1057.

19. ICH Validation of Analytical Procedures: Text and methodology Q2 (R1), International Conference on Harmonization, 2005. 